\title{
Imaging Spectroscopy as a Quantitative Tool for the Retrieval of Biogeophysical Parameters
}

\author{
Michael Schaepman, Klaus I. Itten, Zurich \\ Michael Rast, Noordwijk
}

\section{Introduction}

Various efforts in environmental policy on a global level have improved the awareness of the need to monitor geophysical parameters with new techniques. The much referred to Kyoto Protocol to the UN Framework convention on Climate Change (UNFCC) proposes a global policy to be applied at international level, based on assessments of carbon emission and sequestration rates. The aim of the protocol is therefore to stabilize the $\mathrm{CO}_{2}$ concentration in the atmosphere in the long run. In particular, the consideration of carbon sinks in the protocol has given a large momentum to the implementation of a scientifically sound accounting and verification system. Key issues still to be resolved are the variability, uncertainty, attribution, non-permanence, leakage and future evolvement of carbon sequestration in the terrestrial biosphere (VALENTINi 2000). The estimated carbon up-take of the biosphere needs to correlate with all other evidence at the three levels of integration of the carbon budget: global, national and local.

We presently lack the understanding and observations needed to complete the annual carbon budget at the global level. Furthermore, it is not yet possible to determine the spatial distribution of carbon sinks at regional and national scales accurately enough. This information however, is crucial for policy making. Recent international research activities highlighted the need for enhanced experimental and monitoring systems (e.g. flux measurements, satellite sensors, field and laboratory experiments, global data archives), which allow for a better parameterisation of terrestrial biosphere models and therefore contribute towards a better understanding of the global carbon cycle and its likely evolution (CRAMER 1999).

Research into the global carbon cycle is organized by many national and international research networks (e.g. the International Geosphere Biosphere Program (IGBP), the World Climate Research Program (WCRP), the Global Change and Terrestrial Ecosystems and Biological Aspects of the Hydrological Cycle projects (GCTE and BAHC), etc.). For many years, the focus of these activities has been on three main components of the Earth system: the terres- trial environment, oceans and atmosphere. The «Great Leap», a joint IGBP and WCRP pilot study, focused on coupled models of physical and biogeochemical systems (land and ocean) in order to understand feedback mechanisms between carbon dioxide and climate. It was found that changing vegetation dynamics play a crucial role in climate-vegetation coupling (Cox et al. 2000).

One particular component of the Earth system, the terrestrial environment, has been identified as being critical for the variability of the global carbon cycle. But given the natural diversity of landscapes, the (instrumented) measurement and validation approach remains challenging. Earth observation from airborne or spaceborne platforms is the only observational approach capable of providing data at the relevant scales and resolution needed to extrapolate findings of in situ (field) studies to larger areas, to document the heterogeneity of the landscape at the regional scale and to connect these findings into a global view. The close coordination of Earth observation satellites and airborne platforms is thus essential for the successful validation of the contribution of the terrestrial component of the global carbon cycle. Space agencies and international organizations have recently established with IGOS-P (Integrated Global Observing Strategy Partnership) a coordination mechanism that facilitates progress in space-based measurements (ESA 2001).

The aim of this contribution is to present new Earth observation platform strategies that enable the reproducible measurement of the radiance field of the terrestrial surface at a local, regional and global scale using well calibrated imaging spectrometers. The derived variables were also used to quantify important processes that are directly relevant for the global carbon cycle. The imaging spectrometers under discussion are APEX (Airborne Prism Experiment) and SPECTRA (Surface Processes and Ecosystem Changes Through Response Analysis), both optimised by design to solve spatial and spectral scaling issues from in situ, regional and global scales.

\section{Relevant Processes and Variables}

The success of an approach using coupled models to link the Earth environment to climate variability is based on the global dynamic representation of vege- 
tation. The understanding of this interaction is based on a suite of models that describe the main processes involved on a local scale over a shorter period of time. The key processes associated with vegetation are photosynthesis, respiration and water transfer because they are the most important drivers of global dynamic vegetation models. This contribution focuses on these three processes and on their monitoring by means of Earth observation instruments. This does not mean to say that other processes are not as relevant and discussed internationally, see the UN Convention to Combat Desertification UNCCD, they are simply not dealt with here.

Photosynthesis is the process by which canopies fix atmospheric carbon into biomass using energy originating from solar radiation. The rate of carbon fixed by the vegetation depends therefore on the amount of photosynthetically active radiation (PAR: integrated radiation energy within the $400-700 \mathrm{~nm}$ spectral range) absorbed by the canopy. The fraction of PAR energy absorbed (fAPAR) depends mainly on the canopy architecture and secondarily on the optical properties of the elements (leaves, stems, trunks, branches, background). The canopy architecture is primarily described using the leaf area index (LAI, leaf area per unit area of soil). Photosynthesis also depends on a large number of other factors, such as carbon concentration in the atmosphere, temperature, mineral deficiencies and nitrogen deficiency. Nitrogen content at leaf level is strongly related to chlorophyll content.

Respiration occurs both within the vegetation (autotrophic) and within the soil (heterotrophic). The soil carbon reservoir is large when compared to the above ground biomass. The understanding of the fluxes of carbon to and from this reservoir (i.e. through litter decomposition and respiration, respectively) becomes a major issue when attempting to calculate the carbon balance. The fraction of dead biomass corresponds to a pool of carbon that can rapidly feed the soil reservoir. Heterotrophic respiration is very dependant on temperature, moisture and availability of nutrients, particularly nitrogen. The nitrogen cycle is therefore intimately linked to the carbon cycle within the soil via the biotic activity.

Water plays a critical role in vegetation canopies, but the soil constitutes the main reservoir of water. Evaporation and transpiration are combined into evapotranspiration to describe the water flux exiting the surface. The latent heat flux necessary to transform the plant and soil liquid water into vapor in the atmosphere closely links evapotranspiration to the radiation energy balance. The energy balance itself is mainly driven by the available incident energy coming from the sun and the sky. Part of this incident energy is reflected towards the sky depending on the albedo of the surface for the shorter wavelengths (fraction of reflected solar energy in the $300-3000 \mathrm{~nm}$ spectral domain), and on the emissivity for the longer wavelengths. The remaining energy is either stored in the soil (soil heat flux), re-emitted in the longer wavelengths (thermal infrared domain) according to the surface temperature and emissivity, or dissipated by convection (sensible heat flux) and evapotranspiration (latent heat flux). The latter two processes are determined by gradients of temperature (sensible flux) or moisture (latent) and by the transfer resistances inherent in the leaf area index and vegetation type (Menenti \& Ritchie 1994).

Finally, many of the processes considered here are influenced by the type of ecosystem or biomes. Ecosystems are built by a collection of species that are organised according to sophisticated rules. Ecosystems tend to adapt themselves to the local pedo-climatic conditions and develop specific strategies for surviving, always submitted to the competition between a large number of species.

From this brief review of the main processes to be found in vegetation, it is apparent that several key variables describing canopy structure as well as the biophysical and biochemical composition of the elements either directly govern the processes or are closely linked to them. Therefore, the Earth observation of these variables should yield pertinent information on vegetation state and condition, thereby contributing towards the description and understanding of dynamic vegetation processes.

\section{Interaction of the radiation field with vegetation}

The interaction of radiation with canopies and soils depends on the optical thermal or dielectric properties of the materials, as well as on their number, area, orientation and position in space, i.e. the primary biophysical variables of the materials. Therefore, remote sensing allows the direct derivation of canopy or soil primary biophysical variables. In addition, secondary variables which are combinations of primary biophysical variables, can also be estimated. The main primary and secondary variables accessible by remote sensing in the solar domain are listed in Table 1.

The information contained in the wavelength range of the solar reflected electromagnetic spectrum $(400-2500 \mathrm{~nm})$ provides estimates of canopy structural variables, such as LAI and the main elements of biochemical composition (chlorophyll and water content). In addition, FourTy \& BAret (1997) demonstrated, that canopy integrated biochemical contents (mass of biochemical constituents per unit soil 


\begin{tabular}{|c|c|c|c|c|}
\hline & \multirow[b]{2}{*}{ Biophysical variables } & \multicolumn{2}{|c|}{ Spectral domain } & \multirow[b]{2}{*}{$\begin{array}{l}\text { Accuracy } \\
\text { requirement for } \\
\text { process description }\end{array}$} \\
\hline & & 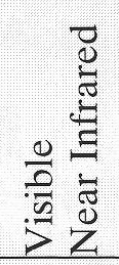 & 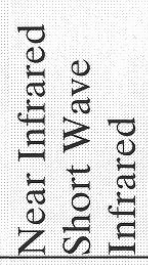 & \\
\hline \multirow{5}{*}{$\begin{array}{l}\text { Canopy } \\
\text { structure }\end{array}$} & LAI & +++ & +++ & $15 \%$ \\
\hline & Leaf orientation & +++ & +++ & - \\
\hline & Leaf size and shape & + & + & - \\
\hline & Canopy height & - & - & - \\
\hline & Canopy water mass & & & - \\
\hline \multirow{2}{*}{$\begin{array}{l}\text { Leaf } \\
\text { characteristic }\end{array}$} & Chlorophyll content & +++ & - & $5 \%$ \\
\hline & Water content & - & +++ & $10 \%$ \\
\hline \multirow{5}{*}{$\begin{array}{l}\text { Soil } \\
\text { characteristic }\end{array}$} & Surface soil moisture & - & + & - \\
\hline & Roughness & + & + & - \\
\hline & Residues & +++ & ++ & - \\
\hline & Organic matter & ++ & ++ & $0.5 \%$ (absolute) \\
\hline & Soil type & ++ & ++ & - \\
\hline \multirow{3}{*}{$\begin{array}{l}\text { Secondary } \\
\text { variables }\end{array}$} & fCover & ++++ & ++++ & $5 \%$ \\
\hline & fAPAR & ++++ & ++++ & $5 \%$ \\
\hline & Albedo & ++++ & +++ & $5 \%$ \\
\hline
\end{tabular}

Table 1. Retrieval potential of biophysical variables as a function of the spectral domain used. The accuracy requirements are derived from measurements, and/or model sensitivity analysis. The level of accuracy and robustness of the estimation is indicated by the «+» («++++» for accurate and robust; «-» indicates no estimates possible).

Herleitungspotential von biophysikalischen Variablen als Funktion ihrer spektralen Eigenschaften. Die angegebenen Genauigkeitsanforderungen für die Prozessbeschreibungen sind von Messungen oder Sensitivitätsanalysen hergeleitet worden. (Die Genauigkeit und Robustheit der Schätzung ist mit «+» und «-» angegeben («++++» sehr genau und robust; «-» keine Schätzung möglich)).

Potentiel de récupération de variables biophysiques en fonction de la gamme spectrale employée. Les conditions d'exactitude sont dérivées de mesures, et/ou de l'analyse de la sensibilité du modèle (l'exactitude et la stabilité de l'évaluation sont indiquées par «+» et «-» («++++» très précis et robuste; «-» aucune évaluation possible)).

Source: BARET 2001

area) were generally more easily accessible than the leaf contents (mass of biochemical constituents per unit leaf area). The canopy-integrated content corresponds to the product of leaf biochemical content and leaf area index.

By summarizing the key variables that can be derived using imaging spectrometer based Earth observation techniques, a new table was compiled (Table 2). The variables are compared with their retrieval uncertainty using «conventional» satellite systems (e.g., SPOT HRV, NOAA AVHRR, Landsat ETM+) with two spectral bands and one view angle, and current highresolution spectro-directional sensors (e.g., MERIS, MODIS, MISR, SPECTRA).

\section{Estimation of canopy biophysical variables}

The increasing use of imaging spectrometer data is gradually enabling more insight into the physical processes involved in the radiative transfer. The classical use of empirical relationships between reflectance observed by the sensors in the spectral, directional, temporal and spatial domains may be seen in simple spectral indices, such as the NDVI (Normalized Difference Vegetation Index). Nowadays these techniques are increasingly making use of radiative transfer models (SELLERS 1985), and more sophisticated methods, such as inverse techniques (PrIVETTE et al. 1996) and assimilation techniques (ASNER et al. 1998), are beoming more common. 


\begin{tabular}{|l|c|c|}
\hline Variable & \multicolumn{2}{|c|}{ Sampling of angular and spectral dimensions } \\
\hline fCover & 1 view angle, 2 spectral bands & Multiangular, hyperspectral \\
\hline fAPAR & $40 \%$ & $5 \%$ \\
\hline Albedo & $30 \%$ & $5 \%$ \\
\hline LAI & $30 \%$ & $2 \%$ \\
\hline \multirow{2}{*}{$\begin{array}{l}\text { Leaf chlorophyll } \\
\text { Leaf water }\end{array}$} & $125 \%$ & $10 \%$ \\
\hline Leaf dry matter & $85 \%$ & $10 \%$ \\
\hline Foliage temperature & Not feasible & $20 \%$ \\
\hline Soil temperature & Not feasible & $20 \%$ \\
\hline $\begin{array}{l}\text { Fraction living/dead } \\
\text { biomass }\end{array}$ & Not feasible & $1{ }^{\circ} \mathrm{K}$ \\
\hline
\end{tabular}

Table 2. Retrieval error for key properties of terrestrial vegetation, based on results of direct and inverse radiative transfer modeling («not feasible» indicates that the accuracy of the retrieval is not sufficient).

Extraktionsfehler für Schlüsselvariablen terrestrischer Vegetation, basierend auf Resultaten von direkter und inverser Strahlungstransfermodellierung («not feasible» bedeutet, dass die entsprechede Variable nicht mit genügender Genauigkeit extrahiert werden kann).

Erreur de récupération pour les propriétés clés de la végétation terrestre, basée sur des résultats de modélisation directe et inverse de transfert radiatif ( «not feasible» indique que la récupération du paramètre avec l'exactitude requise n'est pas faisable).

Source: European Space AgEncy (ESA) 2001

\subsection{Models of canopy reflectance}

Radiative transfer models differ mainly by the way the canopy structure is described and the way the radiative transfer equation is approximated (MYNENI \& ASRAR 1993). Some of the models are more generalistic and others reflect reality closer, i.e. they are detailed but slow. A combination of the two characteristics appears to not be possible due to the heterogeneous distribution of canopy structure over the Earth's surface. Radiative transfer models of canopies exist today in a broad variety and the physical based models usually describe continuous scatterers in turbid mediums (cf. SAIL (VERHOEF 1984)). The decision of which radiative transfer model to use is therefore a critical point in the process of minimising uncertainties in the subsequent inversion and/or assimilation process.

\subsection{Inversion techniques}

The interpretation of imaging spectrometer data with the goal to quantify the spatial and temporal variability of canopy characteristics, whether within or between canopies, is basically an inverse problem. Radiative transfer model inversion provides a way to exploit our knowledge of these physical processes. The physical processes are represented by a radiative transfer model (RT), which can simulate remote sensing data from canopy characteristics. Inversion techniques are designed to retrieve those canopy characteristics that are of interest from imaging spectrometer data. All techniques of interpretation of biogeophysical or biogeochemical products are inversion or assimilation problems requiring the identification of the most relevant measurements from the limited number available (PINTY et al 2000a, b). Generally, all of these techniques suffer from having more than one solution. Greater measurement accuracy contributes to better constraints on the inversion problem, reducing the number of potential solutions. By reducing uncertainties to a level beyond those of the transformation algorithms, imaging spectrometer measurements with many contiguous spectral bands will enable decisions on relative performance and allow quantifiable improvements. We will therefore discuss this particular instrumentation approach in the following section.

\subsection{Instrumentation Approach}

Growing expectations on the use of Earth observation data to support key decisions by governments and industries puts increasing pressure on technology to deliver proven and reliable information. On the one hand, the measurements should be able to document small changes in key terrestrial parameters over many years, and on the other hand, they should be in a form appropriate for pointing to global variability in climate change. Characterisation of these sensor systems is therefore critical, particularly where the systems operate in the solar reflected radiation from the Earth's surface (cf. TeILlet et al. 1999). 
Imaging spectroscopy today enables the geobiophysical and geobiochemical variables of the continental biosphere processes to be measured with quantifiable accuracy. However, surface characteristics critically govern the involved processes. If we want to take proper actions to mitigate these undesirable effects, surface characteristics must be described accurately to better understand, model and predict the interaction between surface and atmosphere. The complex global models that address these issues use variables and parameters to describe the biophysical and biochemical processes but, when compounded, the uncertainties in these variables and parameters can only produce moderate to poorly accurate results. Amelioration comes from independent information applied to control or constrain the models, but the spatially distributed character of land surface processes - large spatial heterogeneity and dynamic character - require remote-sensing observations to provide this information. ESA's (European Space Agency) Living Planet, NASA's (National Aeronautics and Space Administration) EOS programmes and the GMES (Global Monitoring of Environment and Security) initiative recognise this, but there are some remaining uncertainties due to the inherent uncertainty of the measurement.

\subsection{Promise}

Imaging spectroscopy - the quantitative and qualitative characterization of both a surface and the atmosphere using geometrically coherent spectro-radiometric measurements - measures the continuous, upwelling spectral radiance in each spatial pixel. The results can be used for:

1. unambiguous direct and indirect identification of surface materials and atmospheric trace gases,

2. measurement of their relative concentrations,

3. assignment of the proportional contribution of mixed pixel signals (spectral un-mixing problem),

4. derivation of their spatial distribution (mapping problem), and

5. study over time (multi-temporal analysis).

Although biases between sensors, even of the same design like NOAA AVHRR, may limit the detection of subtle temporal changes, «conventional multispectral» remote sensing usually covers aspects $4-5$ with sufficient accuracy. New instruments will cover aspects $1-3$, but conventional calibration techniques will still restrict uncertainties to a few percent at best - thereby being only marginally adequate for current user demands. Even so, imaging spectroscopy has already supported or been used for the following applications and the corresponding variables have been directly or indirectly quantified using inversion techniques (GreEn et al. 1998):

- Calibration, validation and simulation variables

- Atmospheric signatures
- Vegetation in land surface processes

- Geology, soils and minerals

- (Inland) Water quality

- Snow and ice

- Air quality in urban areas

- Detection of hydrocarbonate micro seepage

- Estuary mapping

- Assessment of river floodplains

In addition to these applications, Table 3 lists those variables that have been derived using imaging spectrometers.

As imaging spectroscopy matures, governments, agencies and industry see potential in the utilization of the data and demands for higher spectral and spatial resolution become greater. Climate change, a field that requires long-time base measurements for small changes in specific key parameters to be detected, is an example of one of those fields that rely on higher spectral resolution to be meaningful. The «near-fingerprinting sensors» or «ultraspectral sensors», yet to become fully operational, are an example of the improvements being made in the area of spatial resolution. Preliminary results using Fourier Transform spectro-meters (Yarbrough et al. 2001) demonstrate the feasibility of these sensors to detect fluorescence phenomena in vegetation, which usually occur at spectral bandwidths well below the assumed atmospherically induced effects that exist around $10 \mathrm{~nm}$ bandwidth in the $400-700 \mathrm{~nm}$ range of the electromagnetic spectrum.

\section{The Imaging Spectrometer APEX}

Two major instrumentation approaches are currently being developed, enabling the assessment of quantifiable measurements in the near future. On the local, regional and national scale this is the imaging spectrometer APEX, and on the regional to global scale, the instrument under consideration is SPECTRA (ESA 2001).

Within the framework of the European Space Agency's (ESA) funding scheme PRODEX, an airborne imaging spectrometer named APEX (Airborne Prism Experiment) is currently being developed. APEX is part of the precursor and supporting activities for the future ESA Earth Explorer Core Mission named SPECTRA (ESA 2001). The main mission objectives of APEX are to use the instrument as a simulator, calibrator and validation experiment for planned spaceborne imaging spectrometer missions (e.g. MERIS (Medium Resolution Imaging Spectrometer on ENVISAT) and CHIRS (Compact High Resolution Spectrometer on PROBA)). In addition to that, APEX can act as a radiometric transfer standard for vicarious calibration (SCHAEPMAN \& ITTEN 1998; SCHAEPMAN et al. 2000). The primary use of APEX will be 


\begin{tabular}{|c|c|}
\hline Field & Variables \\
\hline \multirow[t]{13}{*}{ Calibration and Validation } & $\begin{array}{l}\text { NedL (in radiance units) (Noise Equivalent Radiance } \\
\text { Difference) }\end{array}$ \\
\hline & $\mathrm{L}_{\max }$ (in radiance units) (Radiance) \\
\hline & Dynamic range \\
\hline & Polarization for the complete Field of View (FOV) \\
\hline & Linearity \\
\hline & Accuracy of the absolute radiometric calibration \\
\hline & Accuracy of the relative radiometric calibration \\
\hline & $\begin{array}{l}\text { Ground resolution } \\
\text { Swath width }\end{array}$ \\
\hline & Flight altitude $\mathrm{H}$ \\
\hline & Tilting (pointing) possibility \\
\hline & Spectral range \\
\hline & Number of spectral channels \\
\hline & Width of spectral bands \\
\hline \multirow[t]{5}{*}{ Atmospheric Signatures } & Aerosol (total amount) \\
\hline & Water vapor (column) \\
\hline & Aerosol characteristics \\
\hline & Oxygen \\
\hline & Ozone and Methane \\
\hline \multirow[t]{16}{*}{ Vegetation } & Leaf Area Index (LAI) \\
\hline & Leaf orientation \\
\hline & Leaf size and shape \\
\hline & Canopy height \\
\hline & Canopy water mass \\
\hline & Chlorophyll content \\
\hline & Water content \\
\hline & Temperature \\
\hline & Surface soil moisture \\
\hline & Roughness \\
\hline & Residues \\
\hline & Organic matter \\
\hline & Soil type \\
\hline & fCover \\
\hline & fAPAR \\
\hline & Albedo \\
\hline \multirow[t]{6}{*}{ Minerals / Soils } & Iron $\left(\mathrm{Fe}_{2+3+}\right)$ \\
\hline & $\mathrm{AlOH}^{-} \mathrm{MgOH}^{-}$ \\
\hline & Carbonates \\
\hline & Organic carbon \\
\hline & Clay minerals \\
\hline & Soil color, moisture, and roughness \\
\hline \multirow[t]{3}{*}{ Limnology } & Chlorophyll a \\
\hline & Inorganic particulate matter \\
\hline & Gelbstoff (Yellow substance) \\
\hline \multirow[t]{4}{*}{ Snow and Ice } & Grain size \\
\hline & Impurities / Optical depth \\
\hline & Surface liquid water \\
\hline & Seasonal snow cover / fSnow cover \\
\hline \multirow[t]{2}{*}{ Urban (Air Quality) } & Nitrogen oxide $\left(\mathrm{NO}_{2}\right)$ \\
\hline & Ozone $\left(\mathrm{O}_{3}\right)$ \\
\hline
\end{tabular}

Table 3: Summary of successfully retrieved variables using imaging spectrometers.

Zusammenstellung von Variablen, welche mit abbildenen Spektrometern erfolgreich hergeleitet werden konnten. Résumé de variables pouvant être extraites avec succès à l'aide d'imageurs spectraux.

Source: SCHAEPMAN et al. 2001a 


\begin{tabular}{|l|l|}
\hline Parameter & Specification \\
\hline Field of View (FOV) & $\pm 14 \ldots \pm 20$ deg \\
\hline Instantaneous Field of View (IFOV) & $0.48 \ldots 0.70 \mathrm{mrad}$ \\
\hline Flight altitude & $4{ }^{\prime} 000-100^{\prime} 000 \mathrm{~m}$. a.s.l. (7'500 m standard) \\
\hline Spectral channels & VNIR: approx. 140; SWIR: approx. 145 \\
\hline Spectral range & $400-2500 \mathrm{~nm}$ \\
\hline Spectral sampling interval & $400-1050 \mathrm{~nm}:<5 \mathrm{~nm}$ \\
& $1050-2500 \mathrm{~nm}:<10 \mathrm{~nm}$ \\
\hline Spectral sampling width & $<1.5 *$ Spectral sampling interval \\
\hline Center wavelength accuracy & $<0.2 \mathrm{~nm}$ \\
\hline Spectral sampling width accuracy & $<0.02 *$ Spectral sampling width \\
\hline PSF (Point Spread Function) & $\leq 1.75 *$ Sampling interval \\
\hline Smile & $<0.1$ pixel \\
\hline Frown & $<0.1$ pixel \\
\hline Bad pixels & None (requirement after electronics) \\
\hline Scanning mechanism & Pushbroom \\
\hline Absolute radiometric calibration accuracy & $\leq 2 \%$ \\
\hline Storage capacity on board (online $/$ offline) & $>50$ GByte $/>200$ GByte \\
\hline Dynamic Range & $12 \ldots 16$ bit \\
\hline Positional knowledge & $20 \%$ of the ground sampling distance \\
\hline Altitude knowledge & $20 \%$ of IFOV \\
\hline Navigation system, flight line repeatability & $\pm 5 \%$ of FOV \\
\hline Positional and altitude data & Recording of data onto a housekeeping channel \\
\hline Reliability & $99 \%$ successful data acquisitions for all flights \\
\hline Vibration & Anti vibration means \\
\hline Optical head dimensions & Must fit in standard mount \\
\hline
\end{tabular}

Table 4: APEX system specifications APEX Systemspezifikationen Caractéristiques du Système APEX Source: SchAEPMAN et al. 2001a

local, regional and national campaign oriented data acquisition for the quantification of important processes that are directly relevant for the global carbon cycle, and further, for fostering the use of spectroscopy throughout the scientific community. SPECTRA, as opposed to APEX, is a satellite based spectro-directional imager, that will be able to sample a number of test sites world wide within three days at seven different viewing angles and up to 60 programmable spectral bands. In addition to the APEX approach, SPECTRA also makes use of directional thermal infrared $(10.3-12.3 \mu \mathrm{m})$.

Technically, APEX is designed to be a pushbroom imager with approx. 300 spectral channels in the 400 $2500 \mathrm{~nm}$ wavelength region, having 1000 pixels across track and a swath width of $2.5-5 \mathrm{~km}$ depending on flight altitude. The APEX hardware consists of an airborne imaging spectrometer with an optimised spectrometer sensor designed for the detection of land surface proc- esses, a flexible aircraft integration scheme, an internal calibration facility, a laboratory calibration home base, and a Processing and Archiving Facility (PAF) for the generation of calibrated radiance data. A summary of all relevant specifications for APEX is listed in the Table 4 , and its schematic design is illustrated in Figure 1.

The APEX instrument is designed to cover most of the relevant land applications. However, before APEX can do this, a detailed scientific analysis has to be performed and the requirements have to be calculated in terms of SNR (SCHAEPMAN et al. 2001b; SCHLÄPFER \& SchaEpman 2002). Figure 2 lists the dynamic range (minimum and maximum radiance) for the applications investigated. Figure 3 shows the SNR requirements derived for these applications.

APEX development is currently at Phase C/D, meaning that the industrial design and manufacturing phase is completed and planned completion of the instrument 

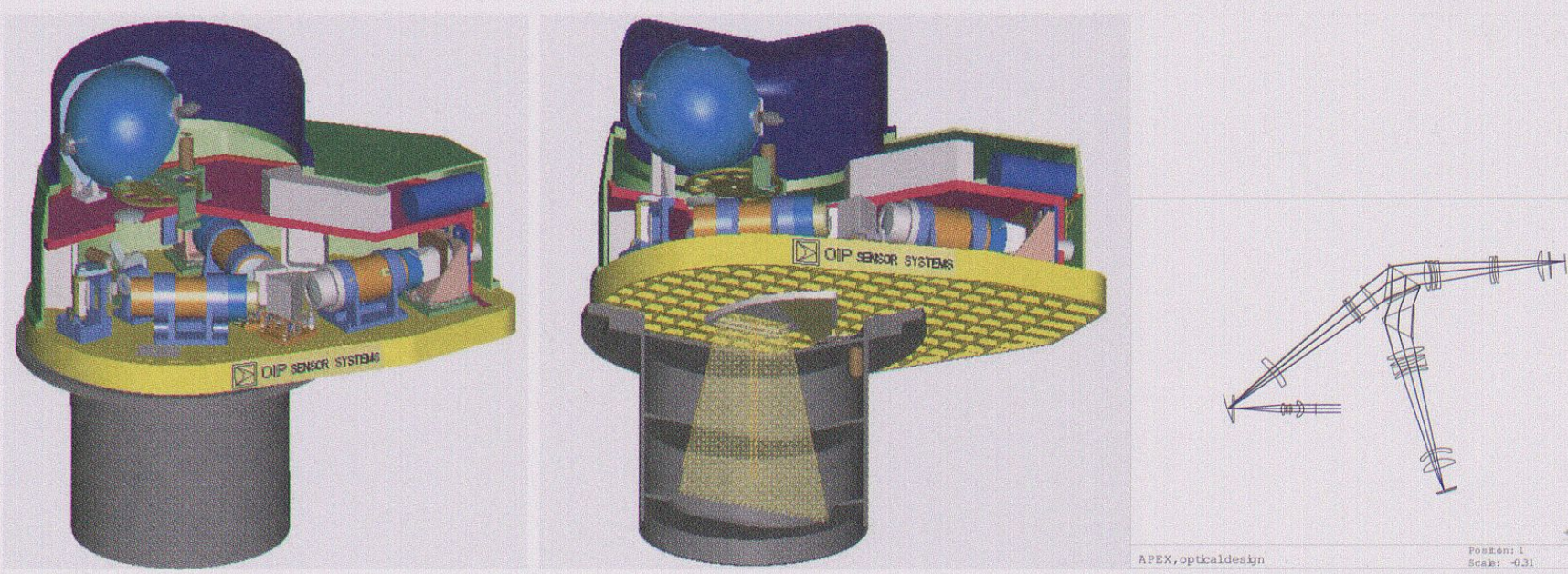

Figure 1: APEX schematic drawings: Front view with three levels: optical bench (bottom), electronics (middle), calibration unit (top) (left); baffle alignment and beam projection (middle); optical 2 prisms design (right).

Schematische APEX Zeichnungen: Frontalansicht mit der optischen Bank (unten), der Elektronik (Mitte) und der Kalibrationseinheit (oben) (links); Streulichtschutz und Projektion der Aufnahme (Mitte); optisches Design mit den zwei Prismen (rechts).

Diagrammes schématiques d'APEX: Vue de face avec trois niveaux: banc optique (fond), composants électroniques (milieu), unité de calibrage (dessus) (gauche); l'alignement de cloison et projection du faisceau (milieu); conception optique en deux prismes (droite).

Source: (C) OIP Sensor Systems

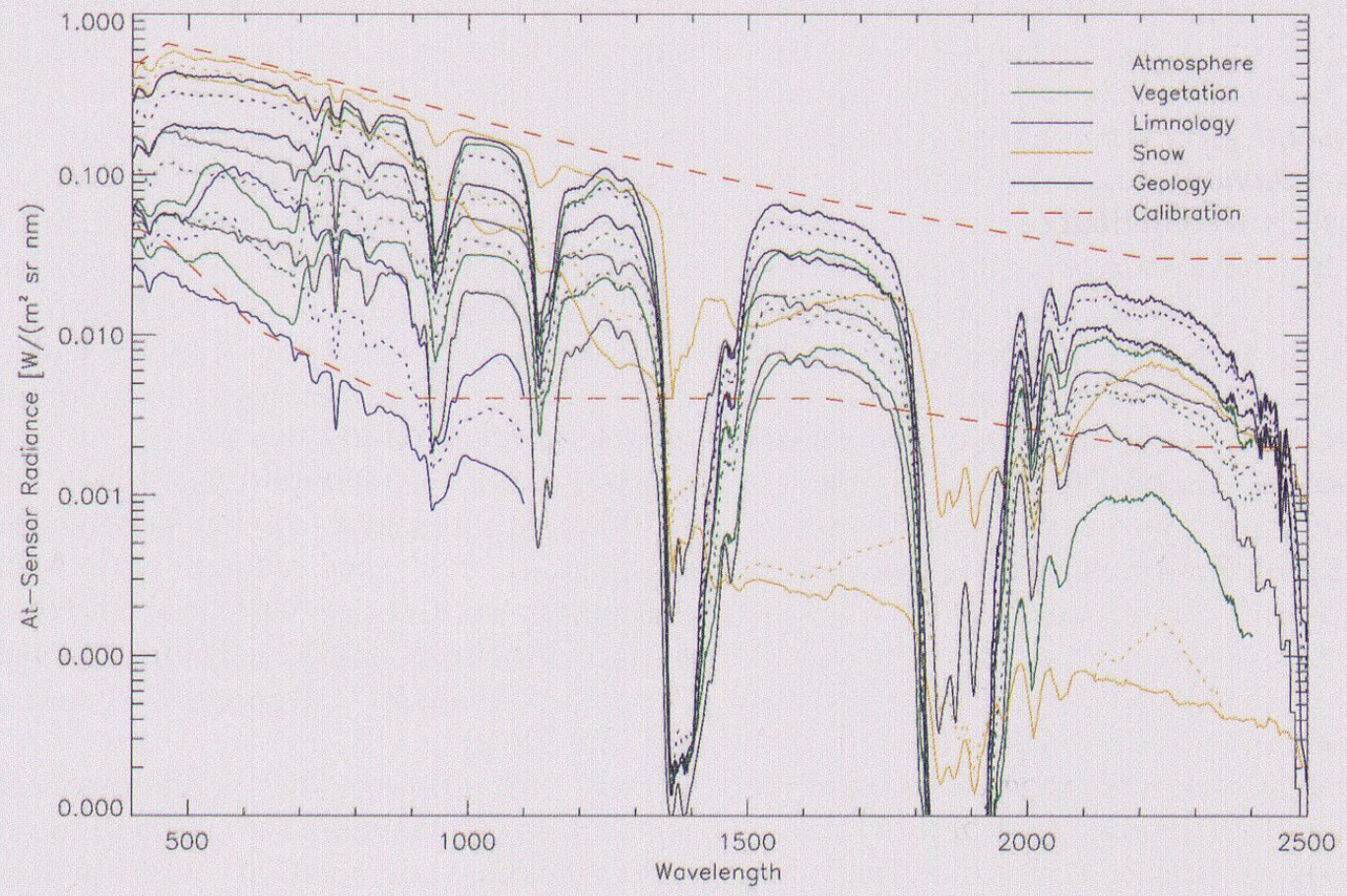

Figure 2: Minimum and maximum radiance levels for six land applications in the solar reflected wavelength range

Minimale und maximale Strahlung für sechs terrestrische Anwendungen im solar reflektiven Bereich des Spektrums

Minima et maxima de radiance pour six applications terrestres dans la gamme de longueurs d'onde reflétées par le soleil

Source: SchaEPMAN et al. 2001b 


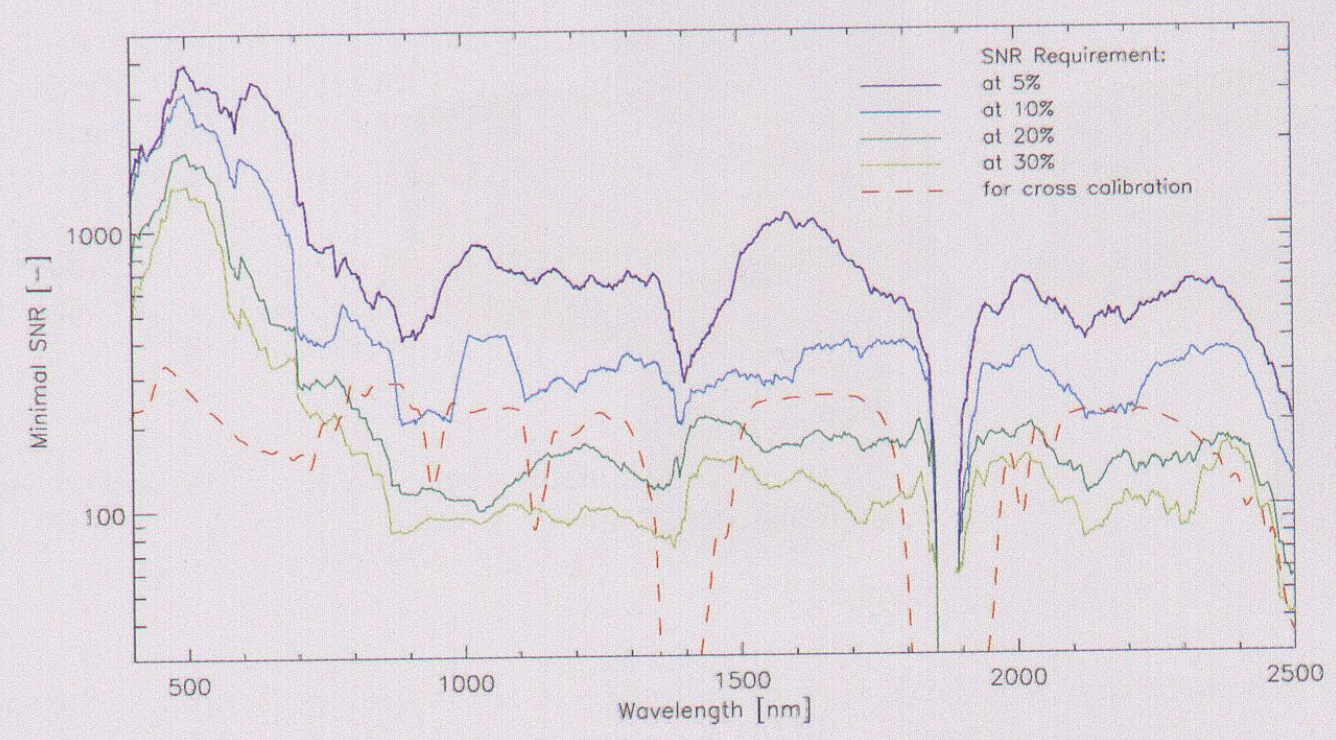

Figure 3: Calculated Signal to Noise Ratios (SNR) for APEX using a forward spectral model Berechnetes Signal-Rausch-Verhalten für APEX basierend auf einem spektralen Vorwärtsmodell Rapports signal-bruit calculés pour l'APEX d'après un modèle spectral direct

SOurce: SCHLÄPFER \& SCHAEPMAN 2002

is scheduled for 2005. The operational phase of APEX is foreseen for a duration of 5 years from VITO in Belgium and should be completed in time for the planned launching of the SPECTRA Earth Explorer Core Mission in 2008. The industrial team responsible for the construction of APEX is composed of the Swiss companies HTS AG (industrial prime, system integration) and Netcetera AG (mission software, electronics), the Belgian company OIP Sensor Systems (spectrometer), the French company Sofradir (detectors), and the German company DLR (calibration home base, airworthiness certification). ESA is responsible for the technical project management and contractual issues. The scientific team and the Principal Investigator are situated at the University of Zurich, Switzerland.

\section{Acknowledgements}

This research is being performed in the context of the ESA PRODEX and EO-EP programmes with support from the Swiss National Science Foundation (Proj.-No. 2000-061431) and the University of Zurich, Switzerland. We would like to acknowledge the contributions made by the Mission Advisory Group (MAG) of the ESA Earth Explorer Core Mission SPECTRA (ESA 2001).

\section{References}

Asner, G.P., Wessman, C.A. \& D. S. Schimel (1998): Heterogeneity of savannah canopy structure and func- tion from imaging spectrometry and inverse modelling. - In: Ecological Applications 8, 1022-1036.

BARET, F. (2001): Variables Associated to vegetation processes and retrieval prospects from high spectral resolution imaging systems. - In: SchaEPMAN, M.: APEX - Summary Final Report: Technical Note 1, ESA/ESTEC Contract-No. 14906/00/NL/DC, 324 pp.

Cox, P.M., BetTs, R.A., Jones, C.D., Spall, S.A. \& I.J. TOTTERDELL (2000): Acceleration of global warming due to carbon cycle feedbacks in a coupled climate model. - In: Nature 409, 184-187.

Cramer, W. \& C.B. Fields (eds) (1999): The Potsdam NPP model intercomparison. - Global Change Biology $5,1: 1-76$

EUROPEAN SPACE AGENCY (ESA) (2001): SPECTRA Surface Processes and Ecosystem Changes Through Response Analysis. - Reports for Assessment, SP 1257(5), $126 \mathrm{pp}$.

FourTY T., \& F. BARET (1997): Vegetation water and dry matter contents estimated from top of the atmosphere reflectance data: a simulation study. - In: Remote Sensing of Environment 61:34-45.

Green, R., Eastwood, M., Sarture, C. et. al. (1998): Imaging Spectroscopy and the Airborne Visible/ Infrared Imaging Spectrometer (AVIRIS). - In: Remote Sensing of Environment 65: 227-248.

Menenti, M. \& J.C. Ritchie (1994): Estimation of effective aerodynamic roughness of Walnut Gulch watershed with laser altimeter measurements. - Water Resources Research 30: 1329-1337. 
Myneni, R.B. \& G. Asrar (1993): Radiative Transfer in 3-Dimensional Atmosphere Vegetation Media. - In: Journal of Quantitative Spectroscopy and Radiative Transfer 49: 585-598.

Pinty, B., Roveda, F., Verstraete, M., Gobron, N., Govaerts, Y., Martonchik, J., Diner, D. \& R. Kahn (2000a): Surface Albedo Retrieval from Meteosat. 1. Theory. - Journal of Geophysical Research 105, 14: 18099-18112.

Pinty, B., Roveda, F., Verstraete, M., Gobron, N., Govaerts, Y., MartonchiK, J., Diner, D. \& R. Kahn (2000b): Surface Albedo Retrieval from Meteosat. 2. Applications. - Journal of Geophysical Research 105, 14: 18113-18134.

PrivetTe, J.L., EmerY, W.J. \& D.S. Schimel (1996): Inversion of a vegetation reflectance model with NOAA AVHRR data. - Remote Sensing of Environment 58: 187-200.

Schaepman, M. \& K.I. ItTen (1998): APEX-Airborne PRISM Experiment: An Airborne Imaging Spectrometer serving as a Precursor Instrument of the Future ESA Land Surface Processes and Interactions Mission. - In: Proceedings Internat. Soc. for Photogrammetry and Remote Sensing (ISPRS) 22, 7, ISPRS Commission VII Symposium on Resource and Environmental Monitoring, Budapest: 31-37

Schaepman, M., SchläPfer, D., and K.I. ItTen (2000): APEX - A New Pushbroom Imaging Spectrometer for Imaging Spectroscopy Applications: Current Design and Status. - In: Proceedings Internat. Geoscience and Remote Sensing Soc. (IGARSS), Hawaii: 828-830.

Schaepman, M. et al. (2001a): Performance and Calibration Requirements for APEX - Summary Final Report, ESA/ESTEC Contract-No. 14906/00/NL/DC, $28 \mathrm{pp}$.

SCHAePMAN, M., SchläPfer, D. \& A. Müller (2001b): Performance Requirements for Airborne Imaging Spectrometers. -In: Proceedings The Internat. Soc. for Optical Engineering (SPIE), Imaging Spectrometry VII, 4480: 23-31.

SchläPfer, D., \& M. Schaepman (2002): Modelling the noise equivalent radiance requirements of imaging spectrometers based on scientific applications. - In: Applied Optics 41, 27: 5691-5701.

SELLERS, P.J.(1985): Canopy reflectance photosynthesis and transpiration. - International Journal of Remote Sensing 3: 1335-1372.

Teillet P.M., Fedosejevs, G., Gauthier, R.P., Shin, R.T., O'Neill, N.T., Thome, K.J. \& A. Meygret (1999): Quality Assurance and Stability Reference (QUASAR) Monitoring Results for Six Earth Observation Sensors Using Airborne Hyperspectral Data. - International Symposium on Spectral Sensing Research, October 31 to November 4, 1999, Las Vegas, Nevada, on CD-ROM.

Valentini, R., Dolamn, A.J., Ciais, P., Schulze, E.D., Freibauer, A., Schimel, D.S. and M. Heimann (2000):
Accounting for carbon sinks in the biosphere, European perspective. CARBEUROPE. - Max-Planck Institute for Biogeochemistry, Jena, Germany, 17 pp.

VERHOEF, W. (1984): Light scattering by leaf layers with application to canopy reflectance modelling: the SAIL model. - Remote. Sens. Environ. 16: 125-141.

Yarbrough, S. et al. (2001): MightySat II.1 hyperspectral imager: summary of on-orbit performance. - Proceedings SPIE, 4480: 186-197.

\section{Summary: Imaging Spectroscopy as a Quantitative Tool for the Retrieval of Biogeophysical Parameters} Representing the dynamic character of vegetation in global climate modelling is a challenging task. We present a new instrumentation approach in the form of APEX, an airborne imaging spectrometer to address the key variables and processes relevant for monitoring the biogeophysical and biochemical parameters at the local, regional and national scale. We are able to demonstrate that a large number of relevant processes and variables have been monitored successfully using imaging spectrometers. In particular, the accuracy of the variable retrieval using this observational approach has much improved and the quantification of the interaction of the radiation field with vegetation has been made possible. The airborne instrument APEX will be made available to the scientific community in early 2005, whereas it's space successor SPECTRA is scheduled for launch in 2008. The inclusion of the spectro-directional and thermal components will contribute toward minimizing retrieval uncertainties. Until these instruments are introduced into the market, there is enough time to develop the necessary products and to inform the scientific community about the new possibilities.

\section{Zusammenfassung: Abbildende Spektroskopie als quantitatives Werkzeug zur Extraktion biogeophysi- kalischer Parameter}

Die Repräsentation des jahreszeitlich dynamischen Vegetationsverhalten in globalen Klimamodellen ist eine grosse Herausforderung. In diesem Beitrag präsentieren wir mit APEX ein neues Messinstrument und -verfahren, welches in die Klasse der flugzeuggetragenen abbildenden Spektrometer fällt und mit welchem die relevanten Schlüsselvariablen und Prozesse zur Überwachung von biophysikalischen und -chemischen Parametern detektiert werden können. Diese Detektion geschieht vornehmlich auf lokaler, regionaler und nationaler Ebene. Wir zeigen in diesem Beitrag ebenso, dass es bereits gelungen ist, eine grosse Anzahl dieser relevanten Prozesse mit abbildenden Spektrometern zu messen. Im wesentlichen besteht der Vorteil heutiger Aufnahmestrategien nun aber darin, dass die entsprechenden Variablen mit erhöhter Genauigkeit hergeleitet werden können und dass die Quantifizie- 
rung der elektromagnetischen Strahlung im Zusammenspiel mit der Vegetation möglich ist. Das flugzeuggetragene Instrument mit dem Namen APEX wird der wissenschaftlichen Nutzergemeinde ab 2005 zur Verfügung stehen, und das satellitengetragene Pendant SPECTRA ab 2008. Bei Letzterem kann die Genauigkeit der Messung dank der Einführung von direktionalen und thermalen Komponenten noch einmal verbessert werden. Bis zur Realisierung der Instrumente steht noch genügend Zeit zur Verfügung, um entsprechende Produkte zu entwickeln und die Forschergemeinde mit solchen Daten vertraut zu machen.

\section{Resumé: L'image spectrale, un outil quantitatif de surveillance des paramètres biogéographiques}

La représentation de la dynamique végétative dans des modèles globaux climatiques est une tâche difficile. Nous présentons ici avec APEX un nouvel instrument et une nouvelle technique, un imageur spectral nous fournissant des moyens appropriés pour l'extraction et la surveillance des plus importants paramètres biogéophysiques et chimiques sur une échelle locale, régionale et nationale. Nous démontrons qu'un grand nombre de processus et de variables clé ont déjà été mesurés avec succès à l'aide d'imageurs spectraux. Cette exactitude dans la récupération de variables aidera à la quantification de l'interaction des ondes électromagnétiques avec la végétation. L'instrument aéroporté APEX sera à la disposition de la communauté scientifique dès 2005 , et son complément satellitaire, SPECTRA, est programmé pour un lancement en 2008. La sensibilité thermique et en plusieurs directions de ce dernier aidera à réduire au minimum les incertitudes de récupération. Entre-temps la communauté scientifique pourra dévélopper des méthodes et des programmes qui serviront à l'analyse des données de ces instruments.

\section{Teaching of Geography - pertinent questions}

- Which are the six central issues that have to be dealt with in order to solve the $\mathrm{CO}_{2}$ problem?

- Which three key processes are connected to the monitoring of vegetation? What are those variables called that can be monitored by remote sensing?

- Which five central issues does imaging spectroscopy guarantee to solve? Which of these five could todate not be solved using classical remote sensing?

- What is the reason for retrieving hydrocarbon values?

- What are the advatages expected of the deployment of the new APEX spectrometer and when is the mission expected to take place?

Dr. Michael Schaepman, University of Zurich, Department of Geography, Remote Sensing Laboratories, Spectroscopy Laboratory, Winterthurerstrasse 190, CH-8057 Zurich.

e-mail: schaep@geo.unizh.ch

Prof. Dr. Klaus I. Itten, University of Zurich, Department of Geography, Remote Sensing Laboratories, Winterthurerstrasse 190, CH-8057 Zurich.

e-mail: itten@geo.unizh.ch

Dr. Michael Rast, ESA/ESTEC, Earth Science Division, Postbus 299, NL-2200 AG Noordwijk.

e-mail:michael.rast@esa.int

Manuskripteingang/received/manuscrit entré le 13.2.2003

Annahme zum Druck/accepted for publication/accepté pour l'impression: 5.6.2003 